\title{
The Use of Ships of Opportunity for Irish Sea Based Oceanographic Measurements
}

\author{
Christopher A. Balfour, Michael J. Howarth, Michael J. Smithson, David S. Jones and Jeffrey Pugh
}

\begin{abstract}
Ships of opportunity such as scheduled ferry services offer the potential for cost effective oceanographic measurements to be undertaken with a high temporal resolution. This provides a convenient mechanism to measure near surface water properties as a series of transects along regularly scheduled routes. There are many potential applications for this kind of system which can effectively compliment more traditional approaches to marine based monitoring such as instrumented moorings, buoys, satellite image analysis and dedicated research cruises. Typical applications include environmental monitoring, scientific studies of coastal and shelf seas, and the provision of validation data for numeric modeling and assimilation purposes. One such system or FerryBox has been implemented by Proudman Oceanographic Laboratory (POL) aboard an Irish Sea passenger ferry servicing the Birkenhead to Dublin/Belfast, Ireland routes. This paper discusses the design, implementation and proposed future development of the FerryBox from an engineering based perspective. It is believed that this kind of approach represents a relatively new and novel contribution to marine based measurements and science that is progressively increasing in popularity.
\end{abstract}

Index Terms - Electromagnetic compatibility, Global Positioning System, Instrumented ferry, Oceanographic measurement

\section{INTRODUCTION}

$\mathrm{R}_{\mathrm{t}}$ EGULARLY scheduled ships or passenger ferries offer the potential for marine measurements to be undertaken for a variety of scientific applications [1]-[3]. The now completed European instrumented ferry or 'FerryBox' program promoted the use of ferries and other ships of opportunity for ocean based environmental monitoring [4]-[6]. The Proudman Oceanographic Laboratory (POL) FerryBox was initially commissioned under this EU programme to undertake Irish Sea based measurements as part of a Coastal

Manuscript received March 26, 2007. This work was initially supported by the EU framework IV FerryBox programme (EVK2-CT-2002-00144, www.ferrybox.com) and latterly by the UK Natural Environment Research Council (NERC).

C. A. Balfour is with Proudman Oceanographic Laboratory, Joseph Proudman Building, 6 Brownlow Street, Liverpool, UK. (phone: +44 (0)151 795 4826; fax: +44 (0)151 795 4801; e-mail: cabal@pol.ac.uk).

M. J. Howarth is with Proudman Oceanographic Laboratory, Joseph Proudman Building, 6 Brownlow Street, Liverpool, UK. (e-mail: mjh@pol.ac.uk).

M. J. Smithson is with Proudman Oceanographic Laboratory, Joseph Proudman Building, 6 Brownlow Street, Liverpool, UK. (e-mail: msm@pol.ac.uk).

D. S. Jones is with Proudman Oceanographic Laboratory, Joseph Proudman Building, 6 Brownlow Street, Liverpool, UK. (e-mail: dsj@pol.ac.uk).

J. Pugh is with Proudman Oceanographic Laboratory, Joseph Proudman Building, 6 Brownlow Street, Liverpool, UK. (e-mail: jpugh@pol.ac.uk).
Observatory [7]-[8]. The FerryBox has been installed aboard the NorfolkLine Liverpool Viking (www.norfolklineferries.co.uk) which is one of a fleet of four roll on roll off cargo and passenger Irish Sea ferries. These ferries operate between Birkenhead and either the Belfast or Dublin, Ireland routes on a daily round trip basis for most of the year. With a typical cruising speed of 20 knots, the Birkenhead to Dublin sailing will take about 6 hours to cover the $211 \mathrm{~km}$ route. The Birkenhead to Belfast $250 \mathrm{~km}$ route will take around 7 hours to complete. Fig. 1 shows the ferry track between $28^{\text {th }}$ of November 2006 and $21^{\text {st }}$ December 2006 showing rescheduling of the ferry for a portion of the time to Belfast between $5^{\text {th }}$ and $7^{\text {th }}$ December, with 36 of the total 40 sailings in this period being between Birkenhead and Dublin. Measurements from the FerryBox have been correlated with data from a SmartBuoy [9] at the location shown in Fig. 1.

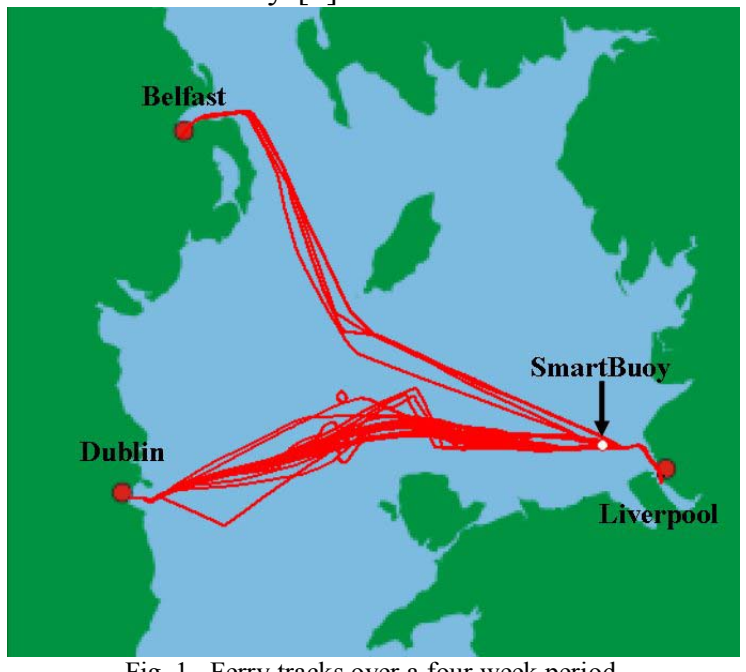

Fig. 1. Ferry tracks over a four week period.

From a scientific point of view, the Irish Sea represents an interesting diverse shelf based sea which is influenced by the Atlantic Ocean at both the north and south entrances [10], [11]. These features combined with coastal processes such as channels, embankments, freshwater mixing and complex tidal currents [12], [13] make the Irish Sea an interesting area for environmental monitoring and scientific study [14], [15]. Therefore, the Irish Sea ferries represent an excellent opportunity to undertake long term studies.

There are essentially two main sections to the Proudman Oceanographic Laboratory instrumented ferry system. On the port side of the lower deck engine room, a sea water chamber has been installed that contains the oceanographic instrumentation mounted inside on a removable frame. During sailings, near surface sea water is pumped through the chamber and the water sampled by the FerryBox 
instrumentation is taken at a distance of $3 \mathrm{~m}$ from the main ferry sea water inlet. This inlet is used for engine cooling purposes and it is at a near surface nominal depth of $-3.5 \mathrm{~m}$. An instrument sample interval of 30 seconds is used that corresponds to a spatial resolution of $300 \mathrm{~m}$. A second system installed in the bridge of ferry is used for data logging and telemetry purposes. Table I lists the basic instrumentation specifications.

TABLE I. BASIC FERRYBOX SENSOR SPECIFICATIONS.

\begin{tabular}{cccc}
\hline Sensor Type & Manufacturer & Range & Accuracy \\
\hline $\begin{array}{c}\text { Conductivity } \\
\text { (electrode) }\end{array}$ & Seabird & 0 to $9 \mathrm{~s} / \mathrm{m}$ & \pm 0.001 \\
\hline $\begin{array}{c}\text { Temperature } \\
\text { (thermistor) }\end{array}$ & Seabird & -5 to $+35^{\circ} \mathrm{C}$ & \pm 0.001 \\
\hline Chlorophyll-a & Chelsea & 0 to $100 \mu \mathrm{g} / 1$ & $\pm 2 \%$ \\
\hline OBS Turbidity & Seapoint & 0 to $25 \mathrm{FTU}$ & $\pm 2 \%$ \\
\hline \hline
\end{tabular}

A service interval of two weeks is normally used to exchange the engine room based sensors, collect data recorded by the CT logger and retrieve data from the GPS receiver installed in the bridge. This service interval is necessary in order to limit the progressive fouling of the instrumentation that will occur over time. Between deployments, laboratory based checks are undertaken to ensure the FerryBox sensors remain within calibration.

\section{The Engine Room Instrumentation System}

The basic arrangement of the engine room instrumentation is shown in Fig. 2. An external 220Vac ship generated mains connection provides the primary source of electrical power, with a battery charger and a sealed lead acid battery proving reserve power for up to 100 hours of operation in the event of an external power failure. The DC output from the battery charger is regulated to $20 \mathrm{~V}$ DC using a linear regulation circuit [16] and low pass ferrite line filters [17] to provide a robust and stable external power source for the oceanographic instrumentation. A RS232 based serial data interface provides a mechanism for communicating with and configuration of the CT recorder when it is installed in the instrumentation chamber. The CT recorder has been programmed to 'echo' the sensor values to its RS232 interface immediately after each value is recorded internally.
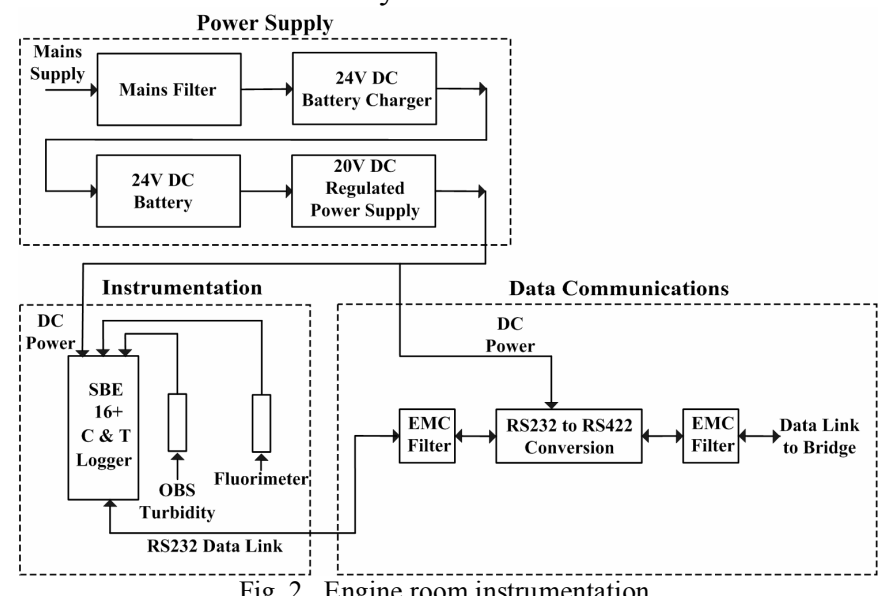

Fig. 2. Engine room instrumentation.

This provides a mechanism to transfer sensor data in real time to the bridge of the ferry using a long data cable. A data conversion interface is then used to transform this RS232 data to differential RS422 signals using commercial RS232 to RS422 converters [18] in order to limit interference and provide higher electrical noise immunity. Before and after the RS232 to RS422 converters, series electromagnetic compatibility (EMC) filters were installed. These EMC filters comprise of ferrite cylinders fitted over each signal lines. The EMC filters shown in Fig. 2 also incorporate low pass inductive filters [19] to effectively de-couple the data conversion unit power supply lines and the data cable common line in local areas of use. These filters provide an additional mechanism to suppress electromagnetic interference (EMI) problems associated with the long direct cable connection of approximately 100 metres between the ferry instrumentation chamber and the bridge. This data communications interface cable provides bi-directional communication with the data logger and telemetry modem installed in the bridge of the ferry using electrically screened, unshielded twisted pair conductor data networking cable (S/UTP). Split core inductive ferrites were also installed at either end of the data cable to further reduce EMI from ship based systems that are located in close proximity to the data cable. A labelled photograph of the instrumentation chamber is shown in Fig. 3a and a photograph of the sensor frame is shown in Fig. $3 b$.

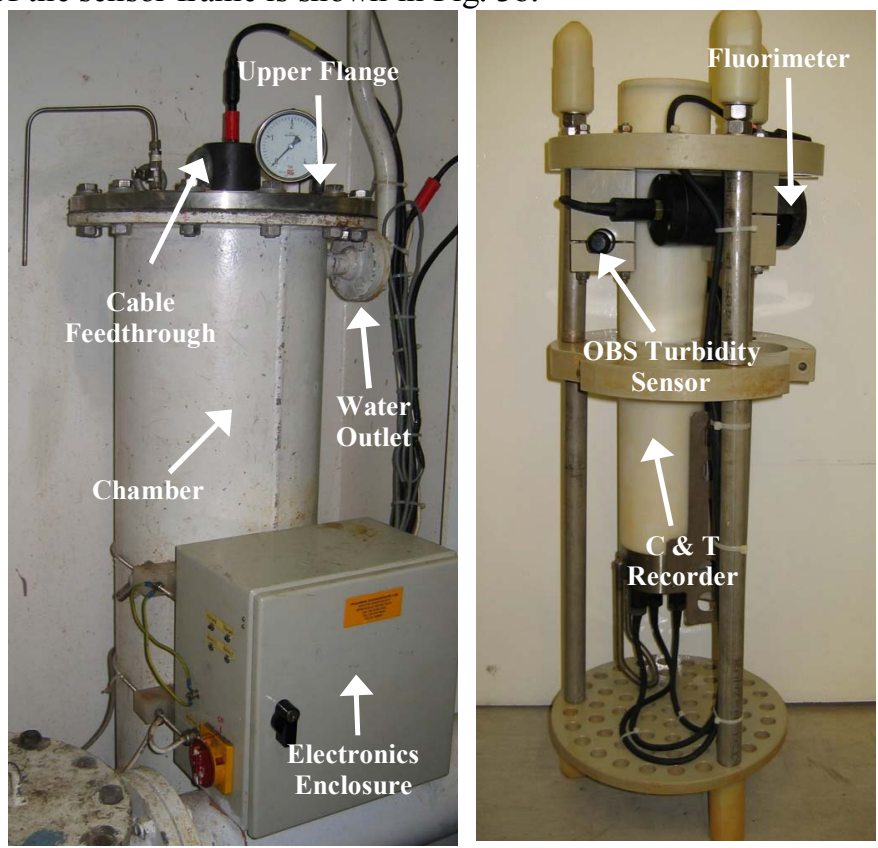

a. The instrumentation Chamber b. Oceanographic sensor frame Fig. 3. Ferry instrumentation chamber and sensor frame

The instrumentation chamber consists of a seam welded $90 \mathrm{~cm}$ tall cylindrical section of galvanised steel with an internal diameter of $30 \mathrm{~cm}$. The chamber is installed in line with the engine cooling water using a $25 \mathrm{~mm}$ bore water inlet at the bottom and a $25 \mathrm{~mm}$ bore outlet pipe coupling at the top. A typical cooling water pressure between 0.5 and 2 bar results in a time between 10-30 seconds to refresh the water in the chamber. A gasket sealed removable stainless steel upper flange allows the instrumentation frame shown in Fig. $3 \mathrm{~b}$ to be installed or removed from the chamber. An air purge valve, pressure gauge and wet pluggable electrical connector have been fitted to the chamber flange. After a routine service visit and instrumentation exchange has taken place, the purge valve allows trapped air to be removed from the chamber during 
refilling with sea water. Due to the internal volume of the chamber, bubbling and subsequent measurement drift does not appear to be a problem. The connector on the upper flange allows data communications along with the provision of external power to the instrumentation frame, and the pressure gauge provides a simple visual display of the current chamber pressure.

\section{The Bridge BAsed Instrumentation System}

A functional diagram of the arrangement used in the bridge area of the ferry is shown in Fig. 4. The system comprises of a Global positioning System (GPS) logger, a satellite telemetry modem, a central data merging/logging unit and a battery backed power supply with a mains driven charging unit. The battery backed supply has an endurance of approximately 3 hours and it is used to provide occasional backup power to the logging and telemetry electronics in the event of an interruption in the ferry mains supply occurring.

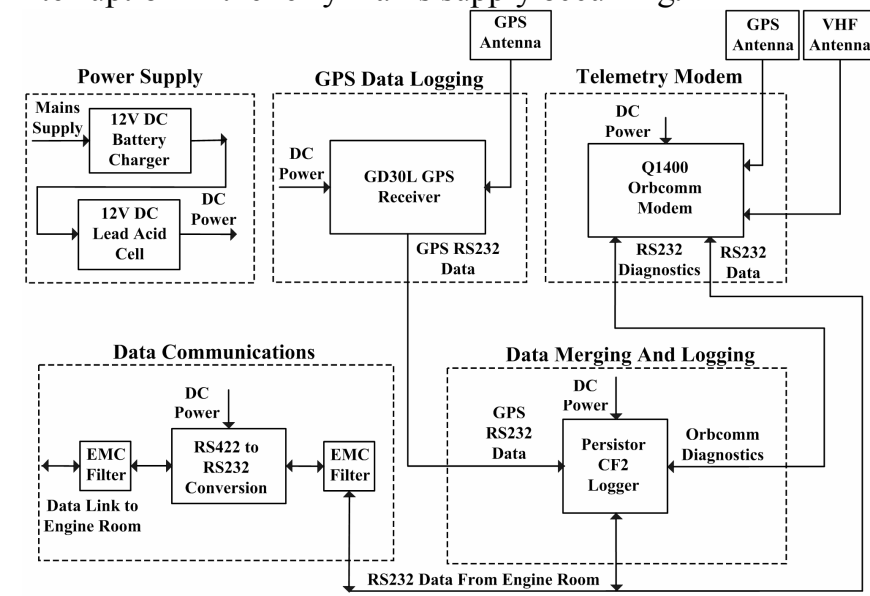

Fig. 4. Bridge based instrumentation.

A commercial GPS logger is used to record the ferry position to removable flash memory at 5 second intervals. This GPS recorder also has the facility to output GPS fix information in the form of NMEA strings [20] via an RS232 interface at one second intervals. A central data logger based upon a CF2 Persistor embedded processor module with a removable flash memory card interface [21] has been used to merge positional and sensor data. The software for the Persistor unit has been specifically written for this application using embedded $\mathrm{C}$ code. The Persistor unit has a RS232 channel that may be used to configure the device for a deployment using a simple terminal emulation program. This configuration channel also acts as a method for recording serial diagnostic information from the telemetry modem once the Persistor logger data recording process has been initiated. A second RS232 serial data channel of the Persistor logger has been programmed to decode data outputted from the GPS logger in the form of RS232 NMEA GPRMC strings. GPRMC is basically a string format that can be parsed to yield the latitude, longitude, date and time at which the GPS fix was measured. Status information relating to the GPS fix validity and a NMEA 'exclusive or' string checksum is also interrogated

A further serial interface on the Persistor logger is used to decode the RS232 sensor data transmitted from the engine room instrumentation after each measurement has been made.
The engine room instrumentation RS232 data is in 'output format 1' from the Seabird CT recorder [22] which consists of a serial character based output of the instrument readings that has been converted into engineering units and represented by ASCII encoded hexadecimal characters. A software algorithm has been devised for the Persistor logger to ensure that the Seabird message is received in the correct structure and format. The seabird message format does not include an error checking mechanism such as a checksum or Cyclic Redundancy Check (CRC) making verification of the integrity of the data received by the Persistor logger from the ferry engine room instrumentation difficult to accomplish. A custom software algorithm has been developed to verify the format and integrity of the Seabird instrumentation message. Tests are also performed on the received measurements to ensure that the decoded values are within the anticipated range of the sensors. This allows any possible data corruption to be detected and erroneous measurements to be ignored. If the received instrumentation message is in the correct format then logging is initiated. This Persistor data logging sequence begins by retrieving the latest GPS fix from volatile memory plus the decoded instrumentation readings, together with the Seabird CT recorder data time stamp. The salinity value from the Seabird sensor readings is then derived. These values are then subsequently recorded to a removable flash memory card within the Persistor unit in the form of an ASCII encoded text file at the frequency that data from the engine room is generated. This process creates a sequence of logged sensor data in real time that includes both a time and positional reference. This effectively merges different measurements taken by multiple systems at different sample rates into a combined data set at a defined sample interval. This allows measurement data to be correlated with both position and time, easing the task of scientific analysis.

The ferry bridge based instrumentation also includes a Quake Global Q1400 telemetry modem [23] for the purpose of near real time measurement data transfer using low earth orbit satellites. This technique was selected due to the lack of a ship based internet connection and very limited Irish Sea coverage by other systems such as GSM. The Q1400 modem is a compact processor system that can be programmed using $\mathrm{C}$ code. The modem has its own integrated GPS receiver, a VHF transceiver and two RS232 data interfaces. One of these serial interfaces is used for configuration of the modem and diagnostic purposes. The other serial interface is used to sample the measurement data transmitted from the engine room instrumentation. This modem is used to transfer FerryBox measurement data via the Orbcomm [24] constellation of low earth orbit satellites to a ground based data downlink. This information is then subsequently routed to Proudman Oceanographic Laboratory in the form of an email attachment. This allows for decoding of the telemetry data and its subsequent publication via the Coastal Observatory web site (cobs.pol.ac.uk/cobs/ferries/). Satellite bandwidth limitations dictated the choice data rate as one measurement every 15 minutes. This means that the telemetry system effectively provides a subset of the logged ferry data and the ferry position in near real time. A real time data compression routine was implemented in the Orbcomm modem to further reduce the volume of data to be transferred by the telemetry 
system. A critical requirement was the satisfactory performance of the telemetry antenna and a series of trials were undertaken to optimize the antenna type and location for this application.

\section{SCIENTIFIC MEASUREMENTS AND RESUlTS}

To illustrate the performance of the engine room to bridge data link, Fig. 5 shows a plot of the percentage of data collected for four 12 day FerryBox deployments. The first two deployments show the effect of EMC problems. This interference is interpreted as activity on the Seabird CT recorder data interface. This in turn leads to an interruption in the logging process or data corruption and subsequent loss of measurement data. Deployments 3 and 4 both exhibited better than $99 \%$ data collection after the EMC filters and RS422 data interface had been installed.

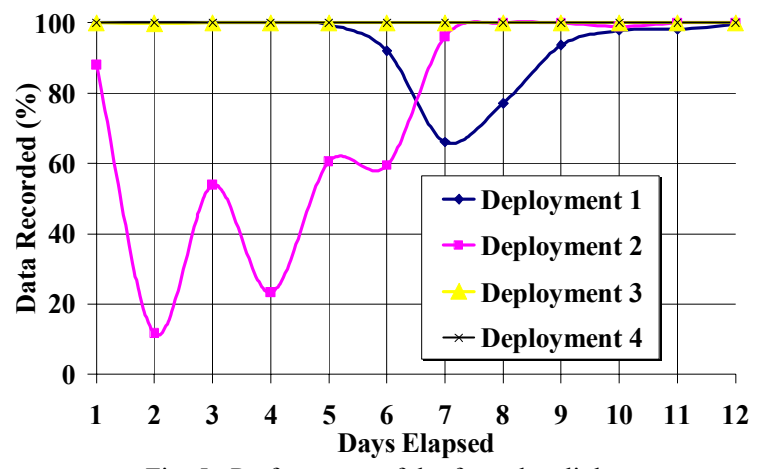

Fig. 5. Performance of the ferry data link.

The measurement of temperature by the FerryBox has proven to be reliable and robust. This is illustrated by the temperature comparison between the FerryBox and SmartBuoy measurements in Fig. 6 for approximately 3 years of data.

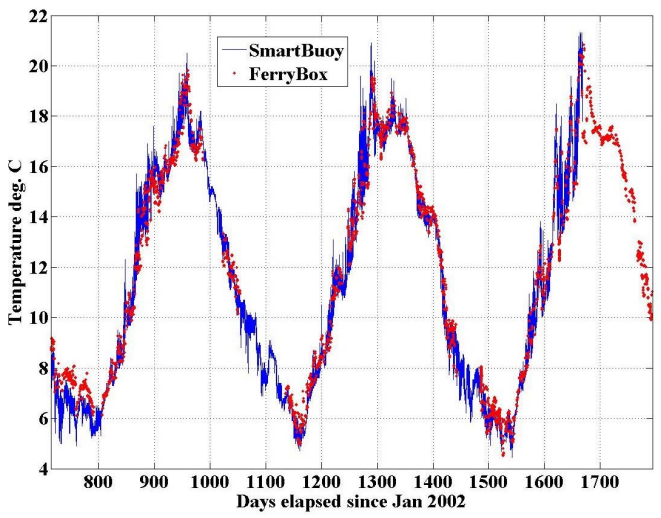

Fig. 6. Long term Seabird to SmartBuoy temperature comparisons

The Seabird measurements of temperature closely match the SmartBuoy readings, with a correlation coefficient of 0.99 and a mean difference of $0.1^{\circ} \mathrm{C}$. This also demonstrates that the temperature measurement inside the FerryBox closely matches the external water surface temperature. The salinity measurement by contrast has proved the most problematic over this time scale and only yielded a correlation coefficient of 0.19 , prompting the investigation into alternative instrumentation. Of particular interest to coastal and sediments processes scientific research is the response of the salinity value to such factors as fresh water mixing variations during seasonal change. Figure 7 show two salinity plots of measurements taken along the same route at different times. The form of the roll off of salinity that occurs during times when the ferry approaches the vicinity of the river Mersey yields valuable scientific information and it is subject to change as illustrated by the two plots in Fig. 7. Unfortunately, the lack of robustness of salinity measurements exhibited by the FerryBox CT recorder, particularly in highly turbid waters close to the ferry ports, has lead to trials to seek a more robust alternative sensing technology.

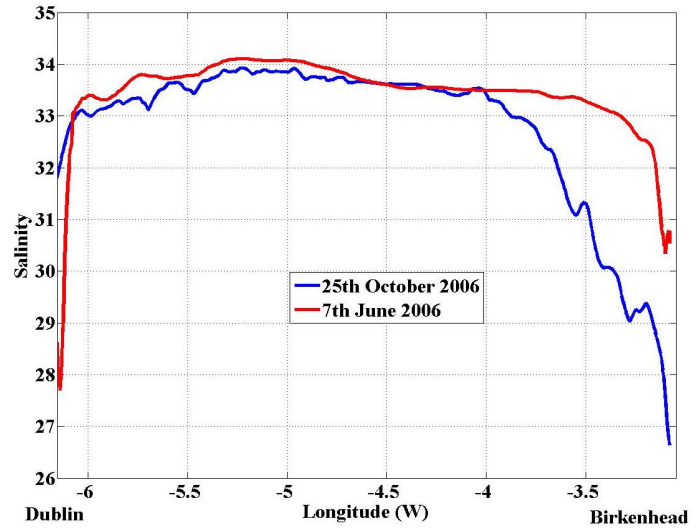

Fig. 7. Salinity profile comparison.

The general form of the salinity value for a typical sailing along with a plot of the effect of sedimentary fouling of the Seabird conductivity cell is shown in Fig. 8. Section A of Fig 8 a represents the salinity profile for a typical sailing from Birkenhead to Dublin during an October 2006 deployment. Section B of Fig. 8a is the profile for Dublin port and section $\mathrm{C}$ represents the salinity change when sailing back to Birkenhead. The effect of sedimentary fouling of the Seabird CT recorder conductivity cell is shown by the decay of the salinity response value to the right of Fig. $8 \mathrm{~b}$ as the ferry approaches the river Mersey.
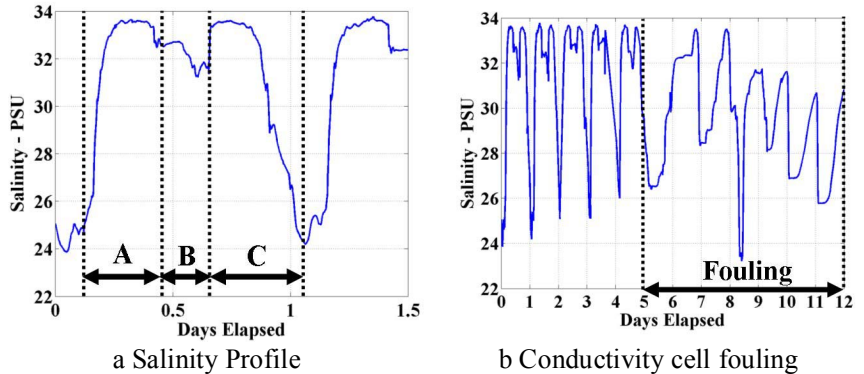

Fig. 8. Salinity measurement

Figure 9 shows a selection of plots illustrating the relative performance of a Seabird CT recorder and a Falmouth Scientific International (FSI) NXIC CTD during a December 2006 simultaneous deployment in the FerryBox. The superimposed plots of salinity in Fig. 9a clearly show sedimentary fouling of the Seabird conductivity cell after about 12 days. In contrast to this, the FSI CTD has sustained the measurement throughout the deployment. For the superimposed plots of Seabird and FSI temperature in Fig. 9c the measurements show good agreement throughout the deployment. Initially the standard deviation of the temperature differences is less than $0.03^{\circ} \mathrm{C}$. However, during the deployment, the Seabird temperature record starts to lag and the difference increases. The most likely cause of this is the 
fouling of the thermistor probe in the Seabird conductivity cell introducing a measurement delay.

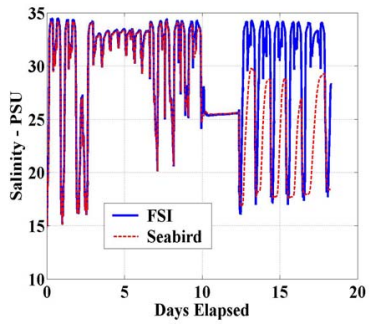

a Salinity measurement comparison

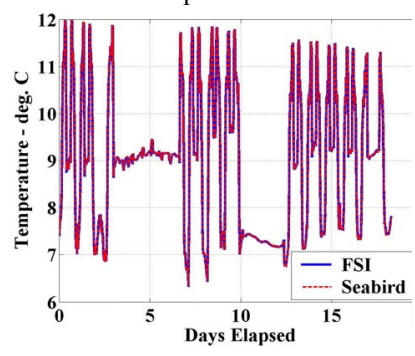

c Temperature measurement

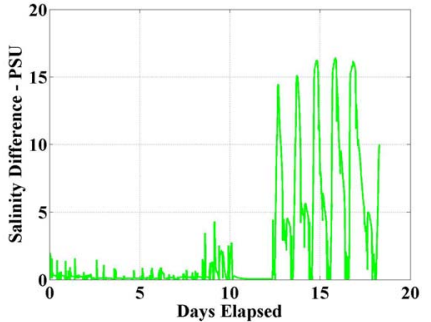

b Absolute difference in salinity

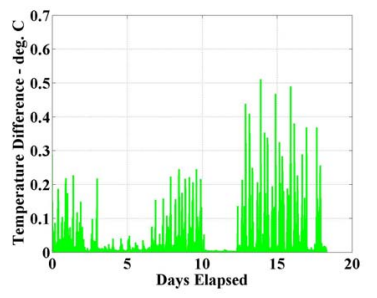

d Absolute difference in temperature
The graphs shown in Fig. 9 have served to demonstrate that in general, the temperature measurement by both types of sensor is robust. Fig. 9 also shows that the electrode type conductivity cell used in the Seabird CT recorder is susceptible to sedimentary fouling. The FSI shielded inductive type conductivity cell, when used in the FerryBox, exhibits a more robust measurement of salinity. A series of forty points along the ferry track were used to compare FerryBox measurements with SmartBuoy measurements for this deployment. Near surface measurements from the ferry were compared within approximately $1.5 \mathrm{~km}$ from the buoy location. A comparison between the ferry and SmartBuoy salinity readings is shown in Fig. 10.

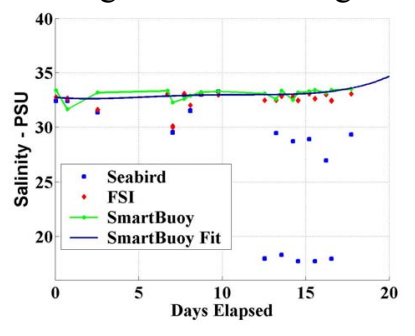

a Salinity comparison

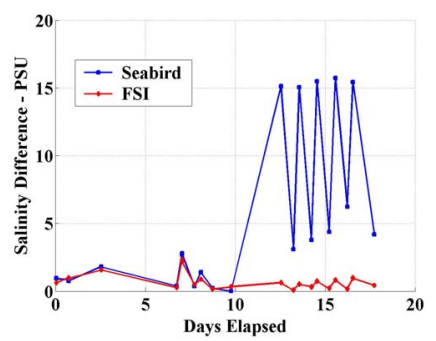

b Difference in salinity values
Fig. 10. FSI and Seabird to SmartBuoy salinity comparisons.

As shown by the graphs, the FerryBox salinity closely matches the SmartBuoy salinity readings for the first half of the deployment. The graph in Fig. 10b clearly illustrates that the Seabird conductivity cell has fouled producing a large difference in readings during the second half of the FerryBox sensor deployment. Figure 10b also shows that the FSI CTD has demonstrated a more consistent measurement during the same time period.

A series of surface plots of the recorded FerryBox measurements are shown in Fig. 11. Each plot shows the recorded values as discrete points during each transect of the Irish Sea. These points are superimposed on an interpolated surface that represents the trend of the measurement during an 18 day deployment beginning in December 2006. For the

temperature and salinity plots in Figs. 11a and $\mathrm{b}$ the measurement is reasonably uniform during each transect with a tendency to reduce when the ferry is in port, as shown by the reduced values in the left and right extremes of these charts. The turbidity plot in Fig. 11c illustrates the effect of sedimentary fouling when the ferry is in port, leading to raised or even saturated readings. The chlorophyll plot in Fig. 10d shows raised values when the ferry is in port due to fouling and a low reading during each transect, due to the reduced algal growth during winter sailings. This demonstrates that the turbidity and chlorophyll measurements remain stable when the FerryBox is operating away from the highly turbid waters that exist in close proximity to each port.

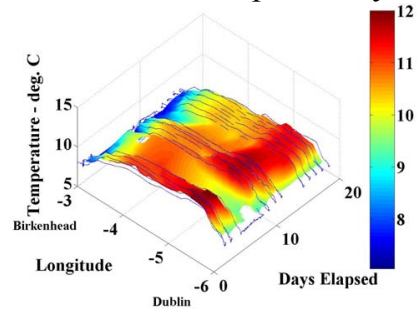

Seabird temperature surface

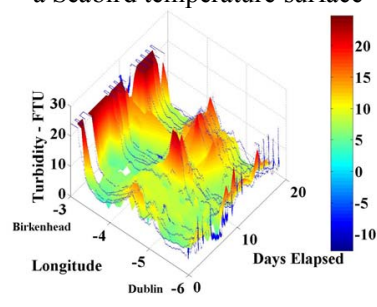

c Turbidity surface

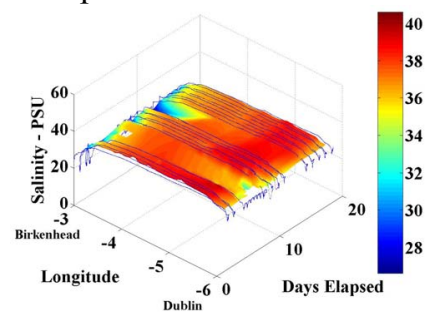

b FSI salinity surface

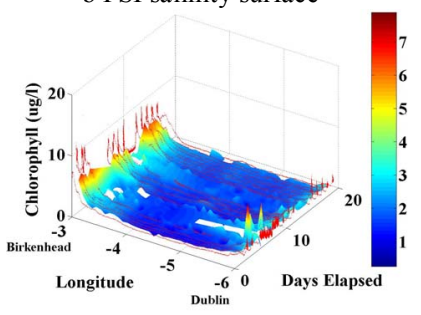

d Chlorophyll-a surface

Fig. 11. Measurement surface plots

\section{DISCUSSION AND FUTURE WORK}

A complex engineering system has been designed that relies upon the successful amalgamation of many distinct technologies. A series of practical trials have been undertaken that have assessed the performance of a suite of ferry based oceanographic sensors. From an end user perspective, this work has also served to highlight some of the shortcomings of commercial instrumentation that can be experienced for this type of application. Methods to circumvent a wide range of the problems experienced have been implemented and future areas of development work to further improve the operation of FerryBox have been identified. Correlation of buoy based measurements has served to further verify the operation of the system. From the point of view of the day to day running of the FerryBox, reliable, quality controlled scientific data for a number of different applications has been generated on an almost all year round basis. To date, the robust measurement of salinity has provided the greatest challenge and trials to asses the effectiveness of different commercial electrode and inductive conductivity sensors have been undertaken.

There are a number of future enhancements that are planned for the FerryBox. To improve the scientific data quality control an automated water sampling system will be installed aboard the ferry. The primary purpose for this is to take specimens of the near surface sea water at known waypoints along the ferry route. Laboratory based measurements of this 
specimen water will allow testing of the oceanographic sensor operation during each deployment. The acute sedimentary fouling of the FerryBox sensors that presently occurs when the ferry is in port will be addressed by the installation of a sensor chamber water inlet flow control valve. The water flow will be turned off automatically close to port areas to prevent excessive instrumentation fouling. The intention is then to trial techniques such as localised chlorination that designed to reduce the effect of biofouling [25]. This will in turn reduce the system maintenance requirements and improve the measurement quality.

An additional ferry will be instrumented to provide more regular data from the Birkenhead to Belfast route. In terms of instrumentation, practical trials will continue with different manufacturer's sensors to assess their suitability for this application. Additions to the suite of oceanographic sensors in use are planned to include the measurement of such parameters as dissolved oxygen, $\mathrm{pH}$, and nutrients. Alternative telemetry systems will be investigated with the goal of providing all of the measurement data in real time via a broadband data link. To publicise the project, a real time graphical display and project description will be installed in one of the decks of the ferry that is designated for passenger use.

\section{ACKNOWLEDGMENT}

The authors whish to acknowledge and express their gratitude to the EU and the UK Natural Environment Research Council (NERC) for the provision of funding to research this activity. NorfolkLine Irish Sea ferries are also acknowledged for their cooperation and support of this project.

\section{REFERENCES}

[1] I. Barton I, and A. Pearce, "Validation of GLI and other satellite-derived sea surface temperatures using data from the Rottnest Island ferry, Western Australia", J. of Oceano. ,62(3), pp. 303-310, June 2006.

[2] O. Schofield, T. Bergmann, P. Bissett, J. F. Grassle, D. B. Haidvogel, J Kohut, M. Moline and S.M. Glenn, "The long-term ecosystem observatory: An integrated coastal observatory", IEEE J. of Oceanic Eng., 27(2), pp. 146-154, April 2002.

[3] R. Williams, S. L. Hedley, P. S. Hammond, "Modelling distribution and abundance of Antarctic baleen whales using ships of opportunity", Ecology and Society, 11(1), June 2006.

[4] V. Fleming and S. Kaitala, "Phytoplankton spring bloom intensity index for the Baltic Sea estimated for the years 1992 to 2004", Hydrobiologica, 554, 57-65, January 2006.

[5] S. E. Holley and D. J. Hydes, "'Ferry-Boxes' and data stations for improved monitoring and resolution of eutrophication-related processes: application in Southampton Water UK, a temperate latitude hypernutrified estuary”, Hydrobiologica, 475(1), pp. 99-110, May 2002.

[6] W. Petersen, F. Schroeder, C. Engelke, "FerryBox: A mature system for operational monitoring - Providing automated observations of coastal waters and estuaries by ships of opportunity", Sea technology, 47(1), pp. $53+$, Jan 2006.

[7] R. Proctor, J. Howarth, P. J Knight, D. K. Mills, "The POL Coastal Observatory - Methodology and some first results, $8^{\text {th }}$ Int. Conf. on Esturine and Coastal Modelling”, pp. 273-287, November 2003.

[8] M. J. Howarth, R. Proctor, M. J. Smithson, R. Player, P. J. Knight, "The Liverpool Bay Coastal Observatory", Proc. of the IEE/OES Eighth Wor. Conf. on Current Measurement Tech., pp. 132-136, June 2005.

[9] D. K. Mills, R.W.P.M. Laane, J. M. Rees, M. R. van der Loeff, J. M. Suylen, D. J. Pearce, D. B. Sivyer, C. Heins, K. Platt, M. Rawlinson, "Smartbuoy: A marine environmental monitoring buoy with a difference", Build. the Eur. Cap. in Op. Oceanog. Proc., 69, pp. 311$316,2003$.
[10] A. M. Davies, P. Hall, M. J. Howarth, P. J. Knight, R. J. Player, "Tidal currents, energy flux and bottom boundary layer thickness in the Clyde Sea and North Channel of the Irish Sea", Ocean Dynamics, 54(2), pp. 108-125, May 2004.

[11] D. J. Hydes, R. J. Gowen, N. P. Holliday, T. Shammon , D. Mills, "External and internal control of winter concentrations of nutrients (N, P and $\mathrm{Si}$ ) in north-west European shelf seas", Estuarine Coastal and Shelf Sci., 59(1), pp. 151-161, January 2004.

[12] S. J. Blott, K. Pye K, D. Van Der Wal, A. Neal A, "Long-term morphological change and its causes in the Mersey Estuary, NW England", Geomorphology, 81(1-2), pp. 185-206, November 2006.

[13] C. F. Jago, S. E. Jones, P. Sykes P, T. Rippeth, "Temporal variation of suspended particulate matter and turbulence in a high energy, tidestirred, coastal sea: Relative contributions of resuspension and disaggregation”, Cont. Shelf Res., 26(17-18), pp. 2019-2028, Nov 2006.

[14] M. E. Charlesworth, M. Service, C. E. Gibson, "The distribution and transport of Sellafield derived Cs-137 and Am-241 to western Irish Sea sediments", Sci. of the Total Env 354(1), pp. 83-92, Jan 2006.

[15] R. J. Gowen, B. M. Stewart, "The Irish Sea: Nutrient status and phytoplankton”, J. of Sea Research 54(1), pp. 36-50, July 2005.

[16] M. Brown, Power Supply Cookbook, $2^{\text {nd }}$ Edn., Newnes, 2001, pp.11-20.

[17] B. Keiser, Principles of Electromagnetic Compatibility, $3^{\text {rd }}$ Edn. Artech House Inc, 1987, p219.

[18] Model 422LP25R Port-Powered RS-232 to RS-422 Converter, B \& B Electronics Ltd, 2003.

[19] P. R. Clayton, Introduction to Electromagnetic Compatibility, $2^{\text {nd }}$ Edn., Wiley, ch. 5, p343-352, 2006.

[20] The NMEA-0183 standard, National Marine Electronics Association, Version 3.01, January 2002.

[21] Persistor CF2 Getting Started Guide, Revision 2.0, Persistor Instruments Inc., July 2005.

[22] SBE 16+ Seacat User's Manual, Version \#013, Seabird Electronics Inc $2005, \mathrm{p} 47$.

[23] The Q1400 Low Cost ORBCOMM Modem for Monitoring and Control, data sheet, QUAKE Global, Inc.

[24] Orbcomm System Overview, A80TD0008-Revision F, Orbcomm Global, L.P., April 2000.

[25] S. Blain, J. Guillou, P. Treguer, P. Woerther, L Delauney, E. Follenfant, O. Gontier, M. Hamon, B. Leilde, A Masson, C. Tartu, R. Vuillemin, High frequency monitoring of the coastal marine environment using the MAREL buoy, J. of Envir. Mon. 6(6), pp. 569-575, 2004. 